\title{
PERANAN AKURASI SISTEM KOMPUTER HOTEL DI FRONT OFFICE DEPARTEMENT DALAM MENINGKATKAN KEPUASAN TAMU DI THE BALAVA HOTEL MALANG
}

\author{
Rio Kurnia Rendra Setiko ${ }^{1}$ \\ Fitria Earlike AS 2 \\ Program Diploma Kepariwisataan Universitas Merdeka Malang1 \\ Jl. Bandung No. 1 Malang
}

Korespodensi dengan Penulis:

Fitria Earlike As: Telp: 081249449443 ; Fax. 0341570371

E-mail: earlike.sani2000@gmail.com

abstract

Front Office merupakan tempat penyediaan informasi selama tamu berada di dalam hotel mulai dari mengatur keberangkatan mereka, termasuk mengelola pembayaran selama mereka tinggal di hotel. Untuk memperlancar pekerjaan Front Office maka hotel menggunakan suatu system yang disebut dengan Emerald System. System ini sebagai salah satu kerangka kerja terbaik dalam mengelola pengendalian teknologi informasi berfungsi untuk mempertemukan semua kebutuhan manajemen dengan cara menjembatani pemisah yang ada resiko bisnis, kebutuhan pengendalian, dan isu-isu teknik. Menurut hasil kuisioner system komputer hotel di The Balava Hotel masih belum akurat dilihat dari jumlah responden yang menjawab "Ya" sebanyak 30\% dan "Tidak" sebanyak 70\% hal ini membuktikan bahwa sistem Emerald banyak mengalami gangguan yang mempengaruhi kinerja karyawan dan membuat tamu lama menunggu sehingga pelayanan yang diberikan karyawan front office kurang maksimal. Sedangkan variable kepuasan tamu di The Balava Hotel Malang menurut hasil kuisioner dapat disimpulkan dari jumlah responden yang menjawab "Ya" sebanyak 49\% dan "Tidak" sebanyak 51\% yang didapat tamu banyak mengeluh saat proses administrasi pada waktu check-in dan check-out, ini menggambarkan bahwa karyawan front office masih belum bisa melakukan pelayanan yang diinginkan oleh tamu.

Kata kunci : Hotel, Front Office, system emerald, kepuasan tamu 
Guna meningkatkan kepuasan tamu, operasional hotel selama periode ini memiliki perubahan yang signifikan dalam peran dan pengaruh teknologi dengan meningkatnya penggunaan komunikasi yang lebih canggih dan terintegrasi. Front office sebagai jantung dari kegiatan utama hotel dituntut untuk menjadi area yang paling perlu diperhatikan karena front office adalah tempat penyediaan informasi selama tamu berada di dalam hotel, mengatur keberangkatan mereka, termasuk mengelola pembayaran.

$$
\text { Menurut Bagyono, }
$$

dalam bukunya yang berjudul Hotel Front Office, Front Office berasal dari bahasa Inggris "Front "yang artinya depan, dan "Office" berarti kantor. Jadi Front Office adalah Kantor Depan. Dalam konteks pengertian hotel, Kantor Depan merupakan sebuah departemen di hotel yang letaknya di bagian depan. Tepatnya tidak begitu jauh dari pintu depan hotel ataulobby. Area ini merupakan tempatyang paling sibuk di hotel. Dengan lokasi di bagian depan maka Front Office termasuk departemen yang paling mudah dicari dan dilihat oleh tamu.
Pendapat Eaum dan Odgers dalam jurnal yang ditulis oleh Baum dan Devine (2007) menyatakan bahwa “They identify the central role of front office in the organization of hotels, both in terms of the flow of management information and in relation to how the guest experiences the range of products and services an offer with the establishment" (p271). Ini artinya, saat ini kegiatan operasional maupun administrasi front office yang bersifat tradisional telah hilang atau telah disederhanakan dengan adanya komunikasi yang canggih dan saling terintegrasi sejalan dengan kebutuhan informasi yang cepat dan tepat bagi para pelanggannya.

Kini banyak perusahaan yang memanfaatkan perkembangan teknologi informasi dalam mengelola seluruh aset perusahaan untuk meningkatkan kinerja bisnis, kualitas data, dan informasi yang dihasilkan, serta kinerja para karyawan. Penerapan teknologi informasi ini tentu dilakukan untuk mencapai suatu tujuan yaitu memperoleh laba atau keuntungan yang maksimal baik secara langsung maupun tidak langsung dan memberikan kepuasan terhadap kebutuhan para pelanggannya. Pada jurnal law dan jogaratnam (2005) 
mengatakan bahwa "Information manusia. Atau akan menjalankan technology (IT) applications in the hotel perintah apa komputer tersebut jika industry have largedy been devoted to the tidak ada softwarenya. Arsitektur Von handling of the routine operational problems Neumann menggambarkan komputer that corp up while running a hotel" (p170). dengan empat bagian utama: Unit Artinya manajer hotel dapat Aritmatika dan Logis (ALU), unit memperkirakan berapa besar laba kontrol, memori, dan alat masukan dan keuntungan dan balik modal yang hasil (secara kolektif dinamakan I/O). diperoleh setiap harinya. Dampaknya Bagian ini dihubungkan oleh berkas bagi front office adalah memungkinkan kawat, "bus".

para pelanggan untuk merasakan

Guna mencapai itu semua, pengalaman yang lebih baik dan staf dibutuhkan kerangka kerja yang telah front office dapat bekerja lebih efisien teridentifikasi dengan baik dan dalam membantu para pelanggannya, memenuhi kebutuhan evaluasi bagi khususnya dalam penyediaan informasi. auditor. Emerald System sebagai salah Sistem Komputer adalah satu kerangka kerja terbaik dalam elemen-elemen yang terkait untuk mengelola pengendalian teknologi menjalankan suatu aktifitas dengan informasi berfungsi untuk menggunakan komputer. Elemen dari mempertemukan semua kebutuhan sistem komputer terdiri dari manajemen dengan cara menjembatani manusianya (brainware), perangkat pemisah yang ada resiko bisnis, unak (software), set instruksi kebutuhan pengendalian, dan isu-isu (instruction set), dan perangkat keras teknik. Emerald System terdiri dari 4 hardware). Dengan demikian komponen domain utama yaitu planning and tersebut merupakan elemen yang organization, acquisition and terlibat dalam suatu sistem komputer. implementation, delivery and support dan Tentu saja hardware tidak berarti apa- monitoring and evaluate. Dengan apa jika tidak ada salah satu dari dua menggunakan Emerald System sebagai lainnya (software dan brainware). dasar evaluasi terhadap system Contoh sederhananya, siapa yang akan informasi, perusahaan dapat menilai menghidupkan komputer jika tidak ada sifat dan tingkat pengendalian teknologi 
informasi yang dibutuhkan untuk Balava Hotel Malang?". Menurut Oka A. mengintregasikan tujuan pengendalian Yoeti (1991:71) mengenai kepuasan tamu internal.

Berdasarkan latar belakang di adalah adanya kepuasan mungkin karena kualitas pelayanan, ketepatan atas, maka permasalahan yang ada waktu, puas karena harganya dan puas dalam penelitian adalah "Bagaimana karena sambutan yang hangat waktu peranan akurasi sistem komputer hotel datang, kepuasan tamu atau pelanggan di front office department dalam didasarkan pada pengalaman dan meningkatkan kepuasan tamu di The harapan-harapan dimasa lalu.

\section{Metode}

Jenis penelitian yang digunakan adalah penelitian deskriptif kualitatif yaitu penelitian tentang data yang dikumpulkan dan dinyatakan dalam bentuk kata - kata yang disusun dalam kalimat dan gambar. Penelitian kualitatif ini untuk memahami fenomena fenomena sosial dari sudut perspektif partisipan.

Metode pendekatan yang digunakan adalah metode pengembangan eksploratif deskriptif yaitu metode strategi menyeluruh untuk menemukan atau memperoleh data yang diperlukan. Pengembangan eksploratif deskriptif yaitu suatu metode untuk memaparkan serta menjelaskan kegiatan atau objek yang diteliti yaitu berkaitan dengan pengkajian fenomena secara lebih rinci atau membedakannya

dengan fenomena yang lain. Definisi konseptual variable dalam penelitian ini adalah variabel (X) adalah Accuracy sistem komputer hotel dan variabel $(\mathrm{Y})$ adalah Kepuasan tamu

Lokasi yang dipilih oleh penulis adalah hotel baru yang ada di kota Malang, yaitu The Balava Hotel Malang tepatnya di Departement Front Office yang berada di jalan Kolonel Sugiono No. 6, Malang. Dengan nomor telepon 0341 2998888 dan fax 0341 - 2997777 alasan dipilihnya lokasi tersebut karena penulis bekerja di hotel tersebut, guna penghematan waktu dan biaya.

Populasi dalam penelitian ini adalah keseluruhan dari department front office dan tamu yang menginap di The Balava Hotel Malang. Pengambilan sampel yaitu mengambil bagian dari staff front office, supervisor, front office 
manager dan tamu yang menginap di The Balava Hotel Malang.

Terdapat dua jenis data yang digunakan dalam penelitian ini, yaitu data primer dan data sekunder. Data Primer adalah data yang diperoleh secara langsung dari sumbernya mengenai masalah - masalah yang menjadi pokok - pokok bahasan melalui wawancara. Data tersebut diperoleh secara langsung dari keterangan sebagian staff front office, front office manager, supervisor, dan beberapa kepala departemen The Balava Hotel Malang. Data Sekunder adalah sumber data sekunder diperoleh dengan membaca berbagai literatur, artikel, majalah, internet dan sumber data lain yang

\section{HASIL}

Dengan adanya sistem emerald pekerjaan karyawan di The Balava Hotel Malang menjadi lebih efisien, tetapi kualitas dari sistem emerald sendiri masih harus lebih di tingkatkan lagi karena masih sering terjadi gangguan pada sistem emerald. seringnya gangguan pada sistem emerald karyawan sering mengeluh karena pekerjaan mereka terganggu, tidak sedikit karyawan yang sering mengganti

berupa dokumen terkait dengan latar belakang dan perumusan masalah.

Pengumpulan data dalam penelitian ini dengan menggunakan teknik pengumpulan data yaitu wawancara, kuesioner dan observasi. Dalam menganalisis data penulis menggunakan teknik deskriptif analitis yaitu memaparkan segala informasi dan data - data yang diperoleh, baik data primer maupun sekunder dan memberikan gambaran secara jelas dan sistematis mengenai fakta - fakta tentang pentingnya teamwork dan komunikasi yang efektif guna meningkatkan kelancaran operasional di front office The Balava Hotel Malang.

rugi dikarenakan tidak akuratnya billing sistem dan harga kamar. Sistem di tengah-tengah pekerjaan sering tidak dapat digunakan dan harus masuk ulang. Sering lambannya sistem membuat tamu jadi menunggu lebih lama. 
Tabel 1. Kuisioner Akurasi Sistem Komputer

Hotel

\begin{tabular}{|l|l|c|c|c|c|}
\hline \multirow{2}{*}{ no } & \multicolumn{1}{|c|}{ Pernyataan } & \multicolumn{3}{|c|}{ Jawaban } \\
\cline { 3 - 6 } & & Ya & $(\%)$ & $\begin{array}{c}\text { Tida } \\
\mathrm{k}\end{array}$ & $(\%)$ \\
\hline 1. & Sistem Emerald bebas dari kesalahan atau akurat & 0 & 0 & 10 & 100 \\
\hline 2. & Informasi atau kinerja sistem Emerald cepat & 3 & 30 & 7 & 70 \\
\hline 3. & $\begin{array}{l}\text { Sistem Emerald berfungsi dengan seharusnya, tidak sering } \\
\text { terjadi kesalahan atau gangguan }\end{array}$ & 0 & 0 & 10 & 100 \\
\hline 4. & Infomasi yang di berikan up to date & 4 & 40 & 6 & 60 \\
\hline 5. & $\begin{array}{l}\text { Penangan gangguan pada sistem dapat ditangani dengan cepat } \\
\text { dan akurat oleh operator Sistem Emerald }\end{array}$ & 4 & 40 & 6 & 60 \\
\hline 6. & Sistem Emerald punya backup data yang akurat & 3 & 30 & 7 & 70 \\
\hline 7. & $\begin{array}{l}\text { Sistem Emerald membantu anda lebih cepat pada proses } \\
\text { administrasi tamu selama tamu check-in sampai check-out }\end{array}$ & 7 & 70 & 3 & 30 \\
\hline \multicolumn{2}{|l|}{ Rata-rata } & & 30 & & 70 \\
\hline
\end{tabular}

Responden 10 orang karyawan front office.

Rusmus Tabel: $\frac{n}{f} \times 100 \%$

n: Hasil kuisioner

f: Total kuisioner yang disebarkan

Dari hasil angket di atas yang telah diberikan kepada 10 orang responden yaitu dari karyawan front office di The Balava Hotel, dapat diketahui khususnya yang berhubungan dengan accuracy sistem komputer hotel dengan melihat angket sebagai berikut.

1. Dibuktikan dengan hasil kuisioner tidak ada yang menjawab Ya dan yang menjawab Tidak 10 orang hal ini membuktikan bahwa sistem emerald sering terjadi gangguan dan tidak akurat dalam memberikan informasi.

2. Dibuktikan dengan hasil kuisioner 3 orang menjawab Ya dan yang menjawab Tidak 7 orang hal ini membuktikan bahwa kinerja dari sistem emerald masih lamban.
3. Dibuktikan dengan hasil kuisioner tidak ada yang menjawab Ya dan yang menjawab Tidak 10 orang hal ini membuktikan bahwa sistem emerald dalam jangka waktu pendek sering terjadi gangguan atau kesalahan sistem.

4. Dibuktikan dengan hasil kuisioner 4 orang menjawab Ya dan yang menjawab Tidak 6 orang hal ini membuktikan bahwa sistem emerald memberikan informasi yang masih kurang update dikarenakan jumlah yang tidak puas dengan kinerja sistem lebih banyak.

5. Dibuktikan dengan hasil kuisioner 4 orang menjawab Ya dan yang menjawab Tidak 6 orang hal ini 
membuktikan bahwa penanganan gangguan pada sistem masih lamban dan kurang akurat

6. Dibuktikan dengan hasil kuisioner 3 orang menjawab Ya dan yang menjawab Tidak 7 orang hal ini membuktikan bahwa sistem emerald belum mempunyai backup data yang akurat dan masih sering salah dalam hasil laporan

7. Dibuktikan dengan hasil kuisioner 7 orang menjawab Ya dan yang menjawab Tidak 3 orang hal ini membuktikan bahwa sistem emerald membantu pekerjaan karyawan front office dalam proses check-in maupun check-out

Sehingga dari uraian penjelasan di atas dapat dikatakan bahwa jawaban $\mathrm{Ya}=30 \%$ dan jawaban tidak $=70 \%$ berarti para karyawan front office di The Balava Hotel Malang masih tidak puas dengan sistem yang sudah digunakan, dan peran operator sistem Emerald harus tanggap terhadap kesalahan sistem yang sering terjadi.

Tabel 2. Kuisioner Kepuasan Tamu

\begin{tabular}{|l|l|c|c|c|c|}
\hline \multirow{2}{*}{ No. } & \multicolumn{1}{|c|}{ Pernyataan } & \multicolumn{4}{c|}{ Jawaban } \\
\cline { 3 - 6 } & \multicolumn{1}{|c|}{ Ya } & $(\%)$ & Tidak & $(\%)$ \\
\hline 1. & Akurasi reservasi sesuai dengan apa yang anda booking & 37 & 37 & 63 & 63 \\
\hline 2. & $\begin{array}{l}\text { Akurasi billing sesuai dengan pemakaian yang sudah } \\
\text { digunakan }\end{array}$ & 31 & 31 & 69 & 69 \\
\hline 3. & Pelayanan sudah efisien pada saat proses check-in & 48 & 48 & 52 & 52 \\
\hline 4. & Pelayanan sudah efisien pada saat proses check-out & 25 & 25 & 75 & 75 \\
\hline 5. & Keluhan tamu ditangani dengan tepat & 77 & 77 & 23 & 23 \\
\hline 6. & $\begin{array}{l}\text { Kemampuan, kesopanan, dan sifat yang dapat } \\
\text { dipercaya mampu diberikan oleh karyawan/ pemilik } \\
\text { kepada tamu }\end{array}$ & 81 & 81 & 19 & 19 \\
\hline 7. & $\begin{array}{l}\text { Karyawan meberikan pelayanan yang ramah terhadap } \\
\text { tamu }\end{array}$ & 69 & 69 & 31 & 31 \\
\hline \multicolumn{2}{|l|}{ Rata-rata } & & 49 & & 51 \\
\hline
\end{tabular}

Jumlah responden 100 orang tamu yang menginap.

Rusmus Tabel: $\frac{n}{f} \times 100 \%$

n: Hasil kuisioner

$\mathrm{f}$ : Total kuisioner yang disebarkan

Dari hasil angket di atas telah diberikan kepada 100 responden yaitu dari tamu yang menginap di The Balava Hotel Malang, dapat diketahui sehubungan dengan kepuasan tamu dengan melihat hasil angket sebagai berikut.

1. Dibuktikan dengan hasil kuisioner 37 orang menjawab Ya dan yang 
menjawab tidak 63 orang hal ini membuktikan bahwa tamu kurang puas dengan pemesanan kamar yang sesuai dengan keinginan kamu.

2. Dibuktikan dengan hasil kuisioner 31 orang menjawab Ya dan yang menjawab Tidak 69 orang hal ini membuktikan bahwa semua pemakaian tamu selama menginap belum sesuai dengan bill yang diberikan kepada tamu, sehingga membutuhkan waktu lebih untuk memperbaiki total keseluruhan bill.

3. Dibuktikn dengan hasil kuisioner 48 menjawab Ya dan yang menjawab Tidak 52 orang hal ini membuktikan bahwa pelayana pada proses check-in masih kurang efisien dan masih membuat tamu menunggu lama.

4. Dibuktikan dengan hasil kuisioner 25 orang menjawab Ya dan yang menjawab Tidak 75 orang hal ini membuktikan bahwa pelayanan pada proses check-out terlalu lama dan tidak akurat.

5. Dibuktikan dengan hasil kuisioner 77 orang menjawab Ya dan yang menjawab Tidak 23 orang hal ini membuktikan bahwa keluhan tamu sudah teratasi dengan cepat dan tepat sehingga tamu mendapatkan apa yang mereka inginkan.

6. Dibuktikan dengan hasil kuisioner 81 orang menjawab Ya yang menjawab Tidak 81 orang hal ini membuktikan bahwa karyawan front office dapat memberi rasa percaya kepada tamu.

7. Dibuktikan dengan hasil kuisioner 69 orang menjawab Ya dan yang menjawab Tidak 31 orang hal ini membuktikan bahwa karyawan front office dapat memberikan pelayanan yang ramah dan nyaman kepada tamu.

Sehingga dari uraian penjelasan di atas dapat dikatakan bahwa jawaban $\mathrm{Ya}=49 \%$ dan jawaban Tidak $=51 \%$ berarti kebanyakan tamu yang menginap di The Balava Hotel Malang masih belum puas dengan pelayanan yang sudah diberikan, pelayanan yang lama pada proses check-in dan check-out dan juga akurasi billing yang kurang akurat membuat sebagian besar tamu kurang puas.

Akibat masalah yang ditimbulkan dari bukti masalah diatas, maka akan timbul akibat sebagai dari masalah tersebut. Akibat yang ditimbulkan adalah : 
a. Sistem komputer hotel yang sering mengalami gangguan menghambat kinerja karyawan front office sehingga tamu menunggu terlalu lama

\section{PEMBAHASAN}

Berdasarkan bukti dan akibat masalah yang telah peniulis kemukakan pada pembahasan sebelumnya, maka dari masalah yang ada tersebut perlu pemecahan masalah yang dihadapi dengan memberikan beberapa alternatif pemecahan masalah sebagai berikut :

a. Operator sistem Emerald harus melakukan pelatihan berkala untuk mengatasi gangguan pada sistem, karyawan front office harus dibekali kemampuan untuk menangani gangguan pada sistem dan diberikan langkah-langkah yang tepat agar bila terjadi gangguan sistem dapat langsung ditangani agar tamu tidak menunggu terlalu lama.

b. Membuat form manual untuk mengantisipasi terjadinya gangguan pada sistem, sehingga disaat sistem sedang mengalami gangguan operasional tidak terganggu b. Front office tidak mempunyai form manual sebagai pengganti sistem

c. Adanya keluhan-keluhan tamu tentang ketidak tepat dan cepat dari kinerja reception

c. Operator Emerald mengawasi dan mengontrol sistem agar tidak sering terjadi gangguan.

Agar alternatif-alternatif diatas dapat dipilih dengan tepat sebagai jalan keluar, maka perlu adanya evaluasi terhadap setiap alternatif tersebut sehingga dapat digunakan sebagai dasar untuk pemecahan masalah yang dapat segera diatasi dan dilaksanakan sebaikbaiknya.

a. Melakukan Pelatihan Secara Berkala Dalam melakukan pelatihan atau training, operator sistem Emerald dapat melakukan pelatihan dalam satu bulan sekali, tiga bulan sekali, atau paling lma enam bulan sekali, untuk menangani gangguan pada sistem. Kelebihan pelatihan secara berkala yaitu memberikan kemampuan kepada karyawan front office agar dapat menangani gangguan pada sistem dan dapat meminimalisir keluhan tamu sebab gangguan mampu di tangani dengan tepat dan cepat. Kelemahannya 
yaitu karyawan front office harus meluangkan waktu diluar jam kerja dan pengeluaran biaya lebih untuk melakukan pelatihan

b. Membuat form manual

Dengan membuat form manual karyawan front office mempunyai backup form yang dapat digunakan sebagai pengganti form yang ada di sistem disaat sistem mengalami gangguan. Kelebihannya yiatu membantu karyawan front office disaat terjadi gangguan pada sistem dan menurunkan resiko tamu menunggu lama karena sudah ada backup form untuk proses administrasi tamu. Kelemahannya yaitu akan lebih banyak mengeluarkan cost sebab akan banyak mengeluarkan kertas dan tinta untuk form manual

c. Melakukan pengawasan dan kontrol runtin

Sering terjadinya gangguan pada sistem operator sis Emerald harus rutin untuk kontrol dan update sistem mereka, agar tidak terus menurus terjadi gangguan. Kelebihannya yaitu meminimalisir terjadinya gangguan dan memberi rasa aman kepada karyawan karena sistem terus diawasi agar akurasinya tetap akurat. Kelemahannya yaitu memerlukan banyak biaya untuk akomodasi operator Emerald

Kesimpulan

Dalam suatu hotel sistem komputer sangatlah penting, sistem dapat membantu pekerjaan manusia sehingga lebih cepat dan lebih akurat, di The Balava Hotel Malang sistem yang digunakan yaitu sistem emerald. Menurut hasil kuisioner system komputer hotel masih belum akurat dilihat dari jumlah responden yang menjawab "Ya" sebanyak 30\% dan "Tidak" sebanyak 70\% hal ini membuktikan bahwa sistem Emerald banyak mengalami gangguan yang mempengaruhi kinerja karyawan dan membuat tamu lama menunggu sehingga pelayanan yang diberikan karyawan front office kurang maksimal.

Kepuasan tamu dalam suatu hotel menggmbarkan suatu kesuksesan pelayanan yang sudah diberikan, di The Balava Hotel Malang pelayan yang diberikan kepada tamu sudah maksimal, tetapi menurut hasil kuisioner dapat disimpulkan dari jumlah responden yang menjawab "Ya" sebanyak 49\% dan "Tidak" sebanyak 51\% yang didapat tamu banyak mengeluh saat proses administrasi pada waktu check-in dan 
check-out, ini menggambarkan bahwa karyawan front office masih belum bisa melakukan pelayanan yang diinginkan oleh tamu.

\section{Daftar Pustaka}

Atmaja. 2011. Analisis Pengaruh Kualitas Pelayanan Terhadap Kepuasan Pelanggan. Universitas Diponegoro.

Gerson,Richard. 2000. Mengukur Kepuasan Pelanggan: Panduan Menciptakan Pelayanan Bermutu. Jakarta : PPM

Khusniatyi. 2007. Sistem Informasi Managemen Perhotelan Dengan Aplikasi Visual Basic Studi Kasus Pada Hotel Puri Indrakila Hotel dan Cottage Ungaran Jurusan Matematika Fakultas dan Ilmu Pengetahuan Alam. Universitas Negeri : Semarang

Manurung, 2002. Management Front Office Hotel. Kesdint Blanc

Soekadijo. 2000. Anatomi Pariwista. Jakarta : Gramedia.

Suyanto, M 2005, Pengantar Teknologi Informasi Untuk Bisnis, Andi Offset, Yogyakarta.

Webster, 2000, Hotel/ Motel Operation an overview, New Jersey.

Whitten, Jeffrey L 2006, Metode Desain dan Analisis Sistem, Edisi 6, Andi Offset, Yogyakarta.
Yoeti, O. A. 1995, Pengantar Ilmu

Pariwisata, Jakarta : Angkasa 